\title{
Adsorption Behavior of Acid-Leached Clays in Bleaching of Oil
}

\author{
I. Z. Mukasa-Tebandeke1 ${ }^{*}$, P. J. M. Ssebuwufu1 ${ }^{1}$, S. A. Nyanzi ${ }^{1}$, G. W. Nyakairu1, \\ M. Ntale ${ }^{1}$, F. Lugolobi ${ }^{2}$, Schumann Andreas ${ }^{3}$ \\ ${ }^{1}$ Department of Chemistry, Makerere University, Kampala, Uganda \\ ${ }^{2}$ Department of Earth Sciences, Wesleyan University, Middletown, USA \\ ${ }^{3}$ Department of Geology, Makerere University, Kampala, Uganda \\ Email: ${ }^{*}$ ishamukasa@cns.mak.ac.ug
}

Received 8 September 2014; accepted 30 April 2015; published 5 May 2015

Copyright (C) 2015 by authors and Scientific Research Publishing Inc.

This work is licensed under the Creative Commons Attribution International License (CC BY).

http://creativecommons.org/licenses/by/4.0/

c) (i) Open Access

\section{Abstract}

The available data have shown that acid-leached clays had sites for adsorption of impurities in oils. Data obtained on residual impurities in cotton and sunflower-seed oils bleached with the same clay materials produced linear Langmuir and Freundlich isotherms. The increase in constant, $k$ with increase in both temperature of thermal activation and concentration of acid used to leach the clay, suggests that bleaching efficiency increased. The value of $n$ decreased with increase in temperature of activation and concentration of acid used to leach the clay suggesting that bleaching capacity increased. The mineral compositions of the clays influenced their surface, structural and bleaching properties.

\section{Keywords}

Adsorption Isotherms, Bleaching, Acid Activation, Clays

\section{Introduction}

Sunflower-seed and cotton-seed oils are some of the vegetable oils which are used widely in food items. Crude vegetable oils are degummed, neutralized and bleached to become fit for human consumption. Diatomaceous earth, clay, peroxide or carbon may be used to bleach and adsorb the dark colored impurities in the oil in order to give it a clear color. Vegetable oils for human consumption are treated with bleaching clays to reduce oil color values by adsorptive purification [1].

A model of isotherm for gases adsorbed to solids was published in 1909 [2]. It is a semi-empirical isotherm

*Corresponding author.

How to cite this paper: Mukasa-Tebandeke, I.Z., Ssebuwufu, P.J.M., Nyanzi, S.A., Nyakairu, G.W., Ntale, M., Lugolobi, F. and Andreas, S. (2015) Adsorption Behavior of Acid-Leached Clays in Bleaching of Oil. American Journal of Analytical Chemistry, 6, 495-512. http://dx.doi.org/10.4236/ajac.2015.66049 
derived from a proposed kinetic mechanism. This isotherm is based on different assumptions one of which is that dynamic equilibrium exists between adsorbed gaseous molecules and the free gaseous molecules. It assumed that the surface of the adsorbent was uniform, that was, all the adsorption sites were equivalent; adsorbed molecules do not interact; all adsorption occurs through the same mechanism; at the maximum adsorption, only a monolayer was formed: molecules of adsorbate do not deposit on other, already adsorbed, molecules of adsorbate, only on the free surface of the adsorbent [2]. Adsorption took place through this mechanism given below:

$$
\mathrm{A}(\mathrm{g})+\mathrm{B}(\mathrm{s}) \rightleftharpoons \mathrm{AB}(\mathrm{s})
$$

where, $\mathrm{A}(\mathrm{g})$ was unadsorbed gaseous molecule; $\mathrm{B}(\mathrm{s})$ was unoccupied metal surface; $\mathrm{AB}$ was adsorbed gaseous molecule; the direct and inverse rate constants are $k$ and $k^{-1}$. Basing on this theory, the equation below was derived to explain the relationship between the number of active sites of the surface undergoing adsorption and pressure.

$$
\theta=\frac{K p}{1+K p}
$$

where, $\theta$ was the number of sites of the surface which were covered with gaseous molecule, $P$ was pressure; $K$ is the equilibrium constant for distribution of adsorbate between the surface and the gas phase. Activated carbon has been used for adsorption of organic substances and non-polar adsorbates. Its usefulness was derived from its large micropore and mesopore volume which lead to high surface area.

An empirical equation for representing the isothermal variation of adsorption of a quantity of gas adsorbed by unit mass of solid adsorbent with pressure [3]. The equation is known as Freundlich adsorption Isotherm; shown below.

$$
\frac{x}{m}=k P^{1 / n}
$$

where, $x / m$ is adsorption per gram of adsorbent which is obtained be dividing the amount of adsorbate $(x)$ by the weight of the adsorbent $(m) . P$ is Pressure, $k$ and $n$ are constants whose values depend upon adsorbent and gas at particular temperature. Though Freundlich Isotherm correctly established the relationship of adsorption with pressure at lower values, it failed to predict value of adsorption at higher pressure. The plot of adsorption per gram of adsorbent, $(x / m)$ versus Pressure gives the Freundlich adsorption isotherm. The value of $x / m$ is increasing with increase in p but as $n>1$ it does not increase suddenly [4].

Taking the logarithms of Equation (3) gives;

$$
\log \frac{x}{m}=\log k+\frac{1}{n} \log P
$$

Plotting a graph of $\log x / m$ is plotted against log $p$ will be a straight line, which is another form of Freundlich isotherm. From this isotherm, the value of slope equal to $1 / n$ and the value of intercept equal to logk can be obtained. This is used to show that the Freundlich adsorption isotherm took place in the system under study.

There are two types of adsorption processes; the physical adsorption which is weak involving van der Waals's forces [3] and chemisorption process leads to covalent bonding forces.

As absorbance measurements were taken in all experiments involving the bleaching processes, the relative quantity of pigment adsorbed, $x$ and the residual relative quantity at equilibrium, $x e$ are obtained from Equations (5) and (6) [5].

$$
\begin{gathered}
x=\frac{A o-A t}{A o} \\
\frac{A t}{A o}=1-x=x e
\end{gathered}
$$

where Ao is the absorbance of unbleached crude oil and At is absorbance of bleached oil at time $t$.

Using Equations (5) and (6) and writing $x e$ instead of equilibrium pressure, $P$ and the residual concentration, $C$; Equations (1) and (2) have been rearranged to Equations (7) and (8) [6]. 


$$
\begin{aligned}
& \frac{x e}{x / m}=\frac{1}{a}+(b / a) x e \\
& \frac{x}{m}=k x e^{n}
\end{aligned}
$$

The Langmuir and Freundlich equations were applied to the adsorption isotherms of $\beta$-carotenes on montmorillonite, activated clay and sepiolite from alkali-refined rapeseed and soybean oils [4].

Application of Langmuir and Freundlich equations to adsorption isotherms for bleaching of crude sunflower seed oil with bentonite, showed that absorbance of bleached sunflower oil decreased as the concentrations of bentonite increased with increase in temperature between $60^{\circ} \mathrm{C}$ and $90^{\circ} \mathrm{C}$ [6]. Successful application of Langmuir and Freundlich isotherms was based the decrease in absorbance of bleached oils as compared to unbleached oils. As kaolinites and smectites were leached in acid, the solid left was mesoporous silica hydrate with high adsorptive capacity. It adsorbed colouring substances as well as nutritive ingredients and oxidation products from the oils very successfully [7]-[13].

Whereas vegetable oil bearing seeds are grown widely in Uganda, establishing the composition of fully processed oils sold in Uganda has never been fully studied. This study has aimed at using the nature of adsorptive processes that occur during bleaching of vegetable oils using clays to characterize the bleaching of oils.

\section{Materials and Methods}

\subsection{Location of Sampled Clays}

The areas from which the clays were mined from Nakawa, Lwanda and Seeta located along Jinja-Kampala Highway. Kajansi clay deposits are on Entebbe road in the Swamp of Kajansi River, Kawuku is located on the shores of Lake Victoria off the Gabba road. Kumi district is located in Eastern Uganda close to the shores of Lakes Bisina. The clay deposits in these areas are mainly sedimentary deposits found along river valleys and swamps. Budadiri and Mutufu clay deposits are found in Sironko district in a characteristically volcanolastic areas yet Chelel and Siron clay deposits are found in Kapchorwa district in areas near Mt Elgon.

While 14 of samples were suspected to contain mainly Kaolinite, six samples smectites. The clays were dug up from virgin mines except for Kajansi, Seeta, Budadiri and Lwanda deposits where clay mines were fully operational. The samples were collected at depths in the range of $35-150 \mathrm{~cm}$ from the surface to reduce contamination and diagenetic effects [14].

Sunflower seeds and cotton seeds were collected from Kampala’s Balikuddembe markets and Jinja oil mills, pressed to collect the different oils. Later samples of sunflower and cotton-seed oils were supplied by Jinja oil mills through Dr. A Schumann.

\subsection{Preparation of Clays}

Raw samples of clays were separately soaked in distilled water, sieved to pass through a mesh $5.3 \times 10^{-4} \mathrm{~m} \mathrm{di-}$ ameter to exclude silica and sand stones, dried and ground to powder using a rolling mill.

\subsection{Leaching of Clays}

Clay powder (10.0 g, $0.02 \mathrm{~mol})$ was mixed with acid $(50 \mathrm{~mL})$ of appropriate concentrations $(0 \%, 5 \%, 10 \%, 20 \%$ $\mathrm{v} / \mathrm{v}$ ) in a flask. The mixture was heated at $105^{\circ} \mathrm{C}$ for 4 hours; then cooled and filtered. The residue was washed to neutrality with distilled water; then dried at $105^{\circ} \mathrm{C}$ in the thermo-stated oven. The dried leached powders were re-ground, labeled and stored for future use.

\subsection{Degumming of Vegetable Oils}

Crude oil (100.0 g, $0.43 \mathrm{~mol}$ ) was placed in a flask, 85\% phosphoric acid (1.0 g, $0.1 \mathrm{mmol})$ was added, the mixture heated at $90^{\circ} \mathrm{C}$ while stirring at 900 revolutions per minute for 10 minutes under nitrogen blanket. The oil was filtered under nitrogen. This method was reported by Car (1978) [14] and modified by Sadia (1992) [15]. 


\subsection{Bleaching of Vegetable Oils}

Degummed neutral oil (200.0 g, $0.85 \mathrm{~mol})$ under nitrogen blanket was passed through columns containing appropriate neutral, acid-leached clay powders $(5.0 \mathrm{~g}, 1.24 \mathrm{mmol})$ separately which had been heat-activated at various temperatures ranging from $40^{\circ} \mathrm{C}$ to $130^{\circ} \mathrm{C}$ for two hours and left to elute bleached oils [7].

\subsection{Adsorption Isotherms of Bleached Oils}

Mixture of the appropriate alkali-refined crude oil (100.0 g) and appropriate clay powders (5.0 g) was placed in $250 \mathrm{~cm}^{3}$ Pyrex glass flask fitted with a magnetic stirrer. The flask was immersed in a thermo-stated iso-electric mantle at temperatures, $40^{\circ} \mathrm{C}, 50^{\circ} \mathrm{C}, 60^{\circ} \mathrm{C}, 70^{\circ} \mathrm{C}, 80^{\circ} \mathrm{C}$ and $90^{\circ} \mathrm{C}$ [16]. The mixture was heated while stirring continuously for a further two hours at the set temperature under high vacuum. The hot oil and clay mixture was filtered in nitrogen atmosphere and tested by measuring its absorbance.

\section{Results and Discussion}

Bleaching involves adsorption of coloring matter on bleaching earths. Therefore a comparison between the absorbance of bleached and unbleached oils is of great importance. The comparison between absorbance of bleached and unbleached oils can be best presented in form of adsorption isotherms. The isotherms portray what takes place in the entire bleaching process at various temperatures. Adsorption isotherms of pigments from alkali refined oils showed that Langmuir and Freundlich equations can be used to elucidate adsorption characteristics of pigments on clays and sepiolites [17].

The absorbance of bleached and unbleached sunflower-seed and cotton-seed oils have been used to study the nature and extent of adsorption of the impurities in crude oils on clay materials [6] [18]. The decrease in absorbance of cotton and sunflower seed oils on being bleached has been explained in a similar way to what was noted when Topallar and Sabah separately observed the 5\% - 20\% reduction in the red color of soybean, canola and palm oils occurred during the bleaching with acid activated bleaching earths [1] [7] [17]. This resulted in breakdown in chlorophyll and carotene concentrations. The increase in adsorption activity of clays after acid treatment is due to the weakness of the Si-O bonds in the clay structures [19].

The absorbance for unbleached, crude sunflower-seed and cotton-seed oils were respectively determined to be 2.583 and 3.383 at $550 \mathrm{~nm}$. The values of absorbance for the bleached sunflower seed oils processed at different temperatures using clays activated with hot acid solutions of varying concentrations were obtained and used to calculate the changes in absorbance and relative absorbance. As absorbance decreased as the temperature of clay activation and concentration of the leaching medium increased, the amount of pigment adsorbed, $x$, increased and the residual relative amount at equilibrium, $x e$, decreased for the bleaching of sunflower and cotton seed oils. The data on relative absorbance is shown in Table 1 and Table 2.

Table 1. Mean Langmuir Data on bleaching sunflower oils $(n=3)$.

\begin{tabular}{|c|c|c|c|c|c|c|c|c|}
\hline \multirow{2}{*}{$\begin{array}{c}\text { Clay } \\
\text { Temp } /{ }^{\circ} \mathrm{C}\end{array}$} & \multicolumn{2}{|c|}{ Kajansi /0\% } & \multicolumn{2}{|c|}{ Kajansi/20\% } & \multicolumn{2}{|c|}{ Chelel/0\% } & \multicolumn{2}{|c|}{ Chelel/10\% } \\
\hline & $x e$ & $x e /(x / m)$ & $x e$ & $x e /(x / m)$ & $x e$ & $x e /(x / m)$ & $x e$ & $x e /(x / m)$ \\
\hline 40 & 0.994 & 168.20 & 0.988 & 81.51 & 0.945 & 17.19 & 0.994 & 168.49 \\
\hline 50 & 0.993 & 160.29 & 0.985 & 65.31 & 0.943 & 16.71 & 0.993 & 152.77 \\
\hline 60 & 0.993 & 152.14 & 0.979 & 47.52 & 0.943 & 16.62 & 0.993 & 134.32 \\
\hline 70 & 0.992 & 134.32 & 0.978 & 45.91 & 0.941 & 15.87 & 0.992 & 119.77 \\
\hline 80 & 0.991 & 119.77 & 0.976 & 40.84 & 0.940 & 15.76 & 0.991 & 104.72 \\
\hline 90 & 0.991 & 104.70 & 0.973 & 40.72 & 0.940 & 15.66 & 0.989 & 88.05 \\
\hline 100 & 0.990 & 101.46 & 0.973 & 40.71 & 0.942 & 16.17 & 0.990 & 101.51 \\
\hline 110 & 0.990 & 101.51 & 0.972 & 35.78 & 0.944 & 16.17 & 0.991 & 108.17 \\
\hline 120 & 0.991 & 104.71 & 0.976 & 40.32 & 0.943 & 16.89 & 0.992 & 124.31 \\
\hline 130 & 0.991 & 111.77 & 0.979 & 46.58 & 0.944 & 16.70 & 0.993 & 134.32 \\
\hline
\end{tabular}


Table 2. Mean Langmuir data on bleached cotton oils $(\mathrm{n}=3)$.

\begin{tabular}{cccccccccc}
\hline & \multicolumn{2}{c}{ Chelel $/ 5 \%$} & \multicolumn{2}{c}{ Kawuku/20\% } & \multicolumn{2}{c}{ Budadiri/20\% } & \multicolumn{2}{c}{ Chelel $/ 20 \%$} \\
\hline Temp $/{ }^{\circ} \mathrm{C}$ & $x e$ & $x e /(x / m)$ & $x e$ & $x e /(x / m)$ & $x e$ & $x e /(x / m)$ & $x e$ & $x e /(x / m)$ \\
\hline 40 & 0.973 & 35.78 & 0.992 & 129.03 & 0.967 & 29.487 & 0.928 & 12.92 \\
50 & 0.972 & 34.86 & 0.990 & 104.70 & 0.964 & 27.409 & 0.925 & 12.37 \\
60 & 0.971 & 34.67 & 0.989 & 95.71 & 0.964 & 26.956 & 0.920 & 11.62 \\
70 & 0.970 & 33.60 & 0.988 & 85.74 & 0.961 & 24.826 & 0.916 & 11.03 \\
80 & 0.967 & 33.51 & 0.986 & 70.99 & 0.958 & 22.992 & 0.914 & 10.66 \\
90 & 0.965 & 27.65 & 0.980 & 51.05 & 0.955 & 21.421 & 0.916 & 10.95 \\
100 & 0.928 & 26.96 & 0.977 & 43.50 & 0.955 & 21.573 & 0.921 & 11.51 \\
110 & 0.964 & 26.50 & 0.975 & 39.81 & 0.956 & 21.727 & 0.922 & 11.92 \\
120 & 0.966 & 28.16 & 0.977 & 44.10 & 0.956 & 21.938 & 0.924 & 12.21 \\
\hline
\end{tabular}

The decrease in absorbance with increase in temperature and concentration of acid used, showed that the bleaching capacity of the clays studied increased [7] [20]. The increase in bleaching ability was caused by removal of octahedral ions from the clay matrices by the acid and dissociation of water to produce hydroxyl groups on the clay surface [21]. For the sunflower and cotton seed oils, the quantity of pigment adsorbed, $x$, mass of clay used, $m$, and the residual relative quantity in equilibrium, $x e$, were separately used to calculate data which showed that effective bleaching occurred for all clays used in the study. The absorbance of bleached cotton-seed oils decreased as the temperature of activation and concentration of the acid in the leaching medium increased. This showed that the amount of pigment adsorbed, $x$, increased and the residual relative amount at equilibrium $x$, decreased for the cotton-seed oils which were bleached.

An isotherm expresses the relationship between the partial pressure of adsorbate gas, or solute concentration in solution, and the surface coverage of the adsorbent at a constant temperature [22]. The Langmuir isotherm has been used to describe the oil pigment adsorption and adsorption of other minor oil solutes during oil processing. A plot of p/n against $\mathrm{p}$ will then produce a straight line [23]. The Langmuir isotherm has been applied to pigment adsorption from vegetable oil in the form of equation 9 below:

$$
\frac{x e}{x / m}=\frac{1}{a b}+\frac{x e}{a}
$$

where $x$ is amount of adsorbed solute, $x e$ is amount of unadsorbed solute, $m$ is grams of adsorbent, $a$ is the surface area of the adsorbent $\left(\mathrm{m}^{2} / 100 \mathrm{~g}\right)$, and $b$ is a constant of the intensity of the adsorption.

The data in Table 1 and Table 2 reveal that effective bleaching occurred in the ranges of temperatures between $40^{\circ} \mathrm{C}$ and $90^{\circ} \mathrm{C}$ because both $x e$ and $x / m$ values decreased within this temperature range for all clays studied and generally increased above $90^{\circ} \mathrm{C}$ [24].

However, the decrease in both $x e$ and $x e(x / m)$ was most rapid for the Chelel clay leached in $20 \%$ acid mixture because the original clay was smectite. So it gained the highest bleaching capability when acid-leached [25].

The data of $x$ and $x e$ for the various clays studied were averaged for each temperature and using the averages, the Langmuir isotherms for each clay plotted as shown in Figure 1 and Figure 2.

As the slopes of the plots given in Figure 1 and Figure 2 increased with increase in temperature used to activate the clays in the range of $40^{\circ} \mathrm{C}$ to $90^{\circ} \mathrm{C}$, it has been inferred that effective bleaching occurred within this temperature range [23]. The graphs in Figure 1 and Figure 2 show that acid-activated clays bleached better when treated with $20 \%$ acid and activated at temperature near $90^{\circ} \mathrm{C}$ [24].

Each plot depicts the decrease in values of Langmuir constants $a$ and $b$ as the temperature increased from 40 to $90^{\circ} \mathrm{C}$. The linearity shown in these Langmuir isotherms indicated that the effectiveness of the adsorptive process for impurities on the clays increased with increase in temperature used to activate the clays. 


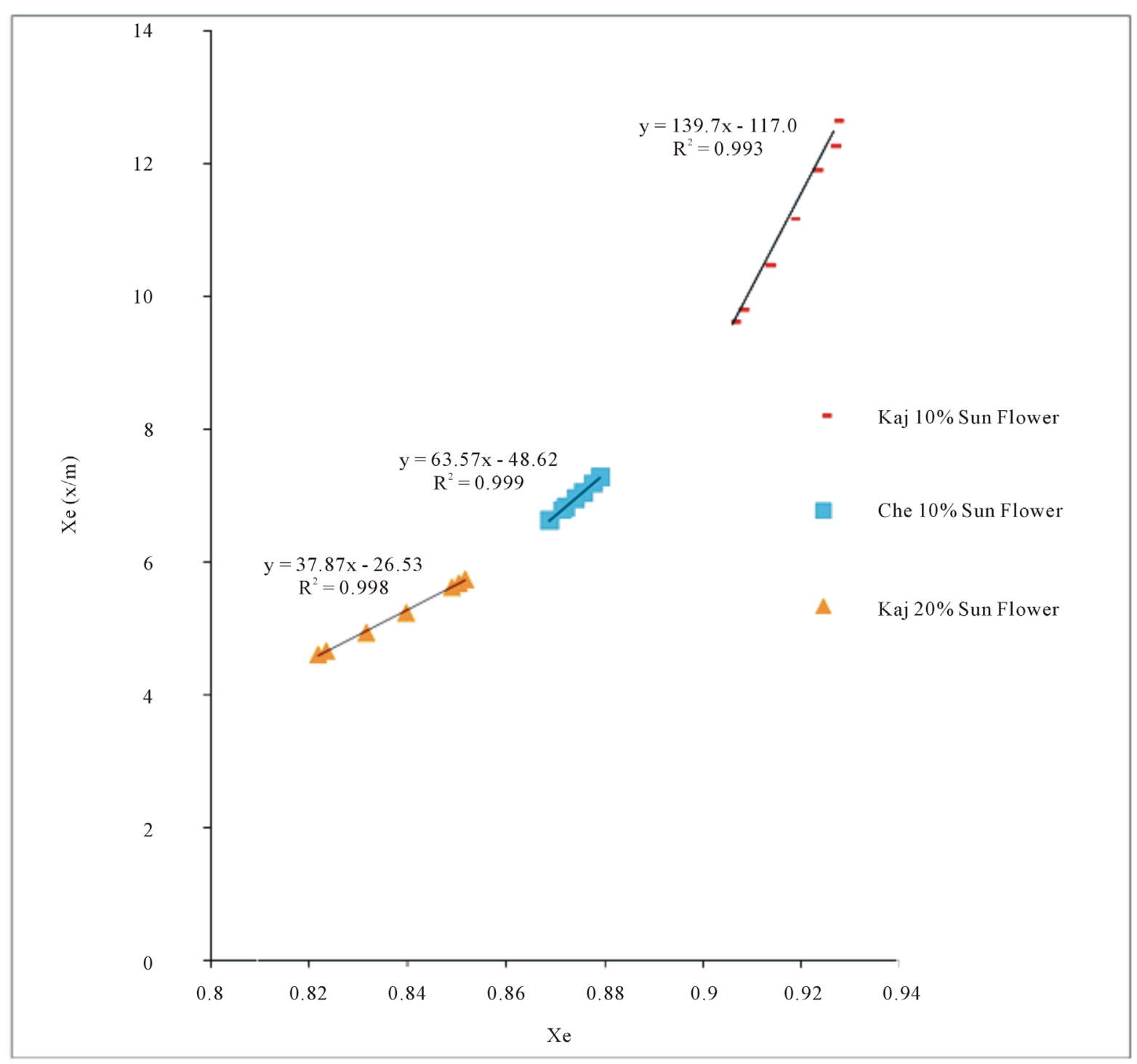

Figure 1. Langmuir isotherms for sunflower oils on Leached clays.

As seen from the Figure 1 and Figure 2 linear graphs resulted showing that Langmuir adsorption isotherms were obeyed when raw and acid-leached clays adsorbed colored impurities from sunflower and cotton-seed oils. The extent of adsorption increased with temperature and clays leached with $20 \%$ acid showed highest adsorptive tendencies. The Langmuir adsorption isotherms for the kaolinite rich clays showed coefficient of linearity, $\mathrm{R}^{2}$ ranging from as low as $0.890 \pm 0.017$ for Seeta and Umatengah clays to as high as $0.998 \pm 0.017$ for Kawuku, Chodah and Kajansi clays. So revealing the clays were weaker at adsorbing impurities. So their capacity to bind coloured impurities was poor because of steric interferences between the adsorbed and free impurities present in vegetable oils being bleached as the kaolinite clays had fewer adsorption sites as compared to smectite clays so leading to saturation of the clay matrix being used [26] [27].

The coefficient of linearity of Langmuir isotherms developed using smectite rich sediments ranged from $0.911 \pm 0.017$ for Budadiri and Siron clays to $0.996 \pm 0.017$ for Mutufu and Chelel clays. Linearity was observed when the soil did not reach saturation with the adsorbate, so the leached smectites could not easily become saturated with impurities from vegetable oils due to presence of many adsorptive sites [28]. Linearity would be extended to higher concentrations of impurity in oils.

The linearity of the isotherms was a function of impurity concentration, availability of surface adsorption sites and interactions between the adsorbed impurities and impurities still remaining unadsorbed in the oil being 


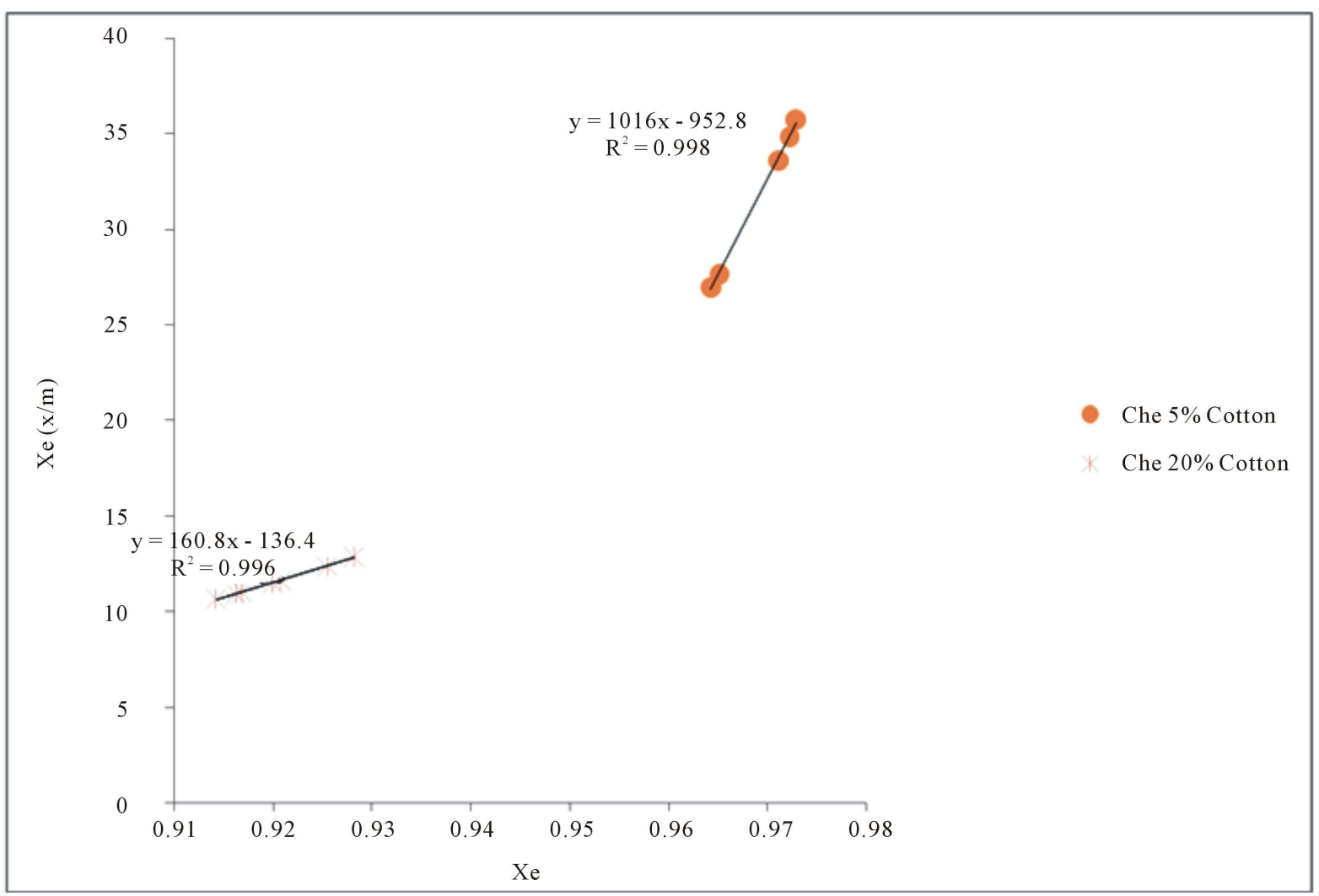

Figure 2. Representative Langmuir isotherms of bleached cotton oils on leached Chelel clay.

bleached [28]. As smectite-rich clays had higher coefficients of linearity than kaolinite-rich clays it can be concluded that acid-leached smectites obeyed Langmuir adsorption more closely than kaolinite-rich clays [29].

For all the clays tested under different conditions of temperature and concentration of acid used to activate the clay, the slopes for the Langmuir isotherms were positive showing that bleaching and surface areas increased with increase in both temperature and concentration of acid used [30]. So linearity would be extended to higher concentration of impurity in oils. Thus the linearity of the isotherms was a function of impurity concentration, availability of surface adsorption sites and interactions between the adsorbed impurities and impurities still remain unadsorbed in the oil being bleached [28]. As long as the clay material did not easily reach saturation with the adsorbed impurities, the Langmuir isotherms obtained were highly linear. The coefficient of linearity reduced as the saturation point for the clay was approached.

It has been noted that clay materials with fewer adsorptive sites easily deviate from linearity of Langmuir isotherms. Similarly, clays whose surface sites have non uniform enthalpies of adsorption also failed to show Langmuir isotherm linearity as the sites were competing for the impurities in the oils being bleached [26] [27]. A comparison of Langmuir isotherms used in studying adsorption characteristics of soils was shown to be limited by the adsorbate concentration [31] [32]. In this study it has been found that once the sorption maximum is exceeded deviations from linearity occur. Nitrogen adsorption data for the characterisation of nanoporous silicas were observed to give excellent linear Langmuir isotherms in the low pressure range and deviated at higher relative pressure [33] [34]. The deviation from linearity of Langmuir isotherms occurs in three regions attributed to existence of surface sites having multiple adsorption free energies [35]. The adsorption of impurities in oils may be governed by impurity-oil and impurity-clay surface interactions [26]. Once steric interferences set in, adsorption is hampered.

The increased linearity as temperature increased for all the clays tested confirmed that the bleaching activity or decolorizing power of the clay matrices increased with increase in temperature up to a maximum at about $90^{\circ} \mathrm{C}$. Although Langmuir behavior is observed when a straight line is obtained when $x e /(x / m)$ is plotted against $x e$, this is not definitive proof of a simple, reversible monolayer, chemisorption mechanism [22]. 
All clays studied bleached optimally at $90^{\circ} \mathrm{C}$, indicating that at this temperature the crystal structure of the clay materials are not greatly changed as crystal water would not have been lost [36]. This further indicated that the water or/and hydroxyl groups in the clay play a major role in the bleaching of vegetable oils [20].

As the gradient of the graphs in Figure 1 and Figure 2 increased positively with increase in concentration of the acid used to leach the clay, acid-activation of the clay greatly enhanced the bleaching capacity of the clay because acid-leaching removed octahedral ions like sodium, magnesium, calcium and potassium ions from the clay matrix which retard bleaching [37]. Removal of octahedral ions left a silica skeleton with enhanced adsorptive properties [38]-[40]. Langmuir constants given in Table 3 decreased with increasing temperature for all clays used, indicating increasing availability of adsorption sites with elevated temperatures because all sites were not energetically equal [17].

Using the reciprocal of the slopes of the Figure 1 and Figure 2, the values of Langmuir constant $a$ were got. The product of Langmuir constant a and the vertical intercept gave values of Langmuir constant $b$ [2] and tabulated in Table 3. Langmuir constants decreased with increasing concentration of acid used to leach the clays as well as the temperature used to activate the clays indicating that acid-leaching and heating to temperatures below $90^{\circ} \mathrm{C}$ increased availability of adsorption sites because all sites were not energetically equal [17].

The values of the Langmuir constants $a$ and $b$ decreased with increase in concentrations of the acid used to leach clay because leaching increased the number of adsorption sites per unit mass of clay. The values of $a$ and $b$ decreased also with increase in the temperature at which the clay was thermally activated; because heat of activation of the clay leads to increase in number of adsorption sites per gram of clay matrix. However, the decrease in values of constants a and $b$ for Chelel clays was higher than for other clays studied because this clay was a smectite.

The values of $a$ and $b$ obtained in this study were less than those obtained by Topallar (1998) using bentonites [7]. However, very close values to those in literature were expected because the forces of adsorption which operate when pure or impure bentonites are used are nearly the same.

The Freundlich isotherm was developed to explain the adsorption of a solute from solution. It is widely used to study oil processing. It is applied as an empirical expression to describe the reversible adsorption of a single solute from aqueous solution at equilibrium at a fixed temperature. The adsorption patterns explain adsorption of vegetable oils pigments onto bleaching clay. The Freundlich isotherms have been useful in finding the commercial value of adsorbents as long as narrow experimental interval of adsorbate is used [41]. A complex series of interactions control the adsorption processes and both Freundlich and Langmuir isotherm simply summarize these interactions [17].

The data in Table 1 and Table 2 have been used to calculate the logarithmic relation given in equation [5] and tabulated in Table 4 and Table 5. The representative Freundlich data in Table 4 and Table 5 give the values of

Table 3. Mean Langmuir constants for vegetable oils $(n=3)$.

\begin{tabular}{|c|c|c|c|c|c|}
\hline \multirow[t]{2}{*}{ Clay } & & \multicolumn{2}{|c|}{ Cotton oils } & \multicolumn{2}{|c|}{ Sunflower oil } \\
\hline & & $a \times 10^{-3}$ & $b$ & $a \times 10^{-3}$ & $b$ \\
\hline Kajansi & $\begin{array}{c}\text { Raw } \\
5 \% \\
10 \% \\
20 \%\end{array}$ & $\begin{array}{l}3.781 \\
2.579 \\
0.589 \\
0.465\end{array}$ & $\begin{array}{l}0.986 \\
0.984 \\
0.965 \\
0.959\end{array}$ & $\begin{array}{l}2.640 \\
0.716 \\
0.384 \\
0.367\end{array}$ & $\begin{array}{l}0.960 \\
0.879 \\
0.838 \\
0.701\end{array}$ \\
\hline Kawuku & $\begin{array}{c}\text { Raw } \\
5 \% \\
10 \% \\
20 \%\end{array}$ & $\begin{array}{l}1.881 \\
0.923 \\
0.331 \\
0.126\end{array}$ & $\begin{array}{l}0.994 \\
0.992 \\
0.987 \\
0.971\end{array}$ & $\begin{array}{l}1.530 \\
1.030 \\
0.840 \\
0.797\end{array}$ & $\begin{array}{l}0.832 \\
0.830 \\
0.807 \\
0.767\end{array}$ \\
\hline Budadiri & $\begin{array}{c}\text { Raw } \\
5 \% \\
10 \% \\
20 \%\end{array}$ & $\begin{array}{l}1.498 \\
0.202 \\
0.149 \\
0.143\end{array}$ & $\begin{array}{l}0.968 \\
0.971 \\
0.950 \\
0.924\end{array}$ & $\begin{array}{l}2.400 \\
1.420 \\
0.972 \\
0.864\end{array}$ & $\begin{array}{l}0.823 \\
0.812 \\
0.806 \\
0.714\end{array}$ \\
\hline Chelel & $\begin{array}{c}\text { Raw } \\
5 \% \\
10 \% \\
20 \%\end{array}$ & $\begin{array}{l}6.219 \\
3.315 \\
0.984 \\
0.066\end{array}$ & $\begin{array}{l}0.983 \\
0.938 \\
0.888 \\
0.845\end{array}$ & $\begin{array}{l}3.251 \\
1.570 \\
1.030 \\
0.884\end{array}$ & $\begin{array}{l}0.821 \\
0.812 \\
0.765 \\
0.671\end{array}$ \\
\hline
\end{tabular}


Table 4. Mean Freundlich data on bleaching sunflower oils $(n=3)$.

\begin{tabular}{ccccccccc}
\hline & \multicolumn{2}{c}{$\mathrm{Kaj} / 5 \%$} & \multicolumn{2}{c}{$\mathrm{Che} / 20 \%$} & \multicolumn{2}{c}{$\mathrm{Bud} / 5 \%$} & \multicolumn{2}{c}{ Che/5\% } \\
\hline $\mathrm{Temp} /{ }^{\circ} \mathrm{C}$ & $\log x e$ & $\log (x / m)$ & $\log x e$ & $\log (x / m)$ & $\log x e$ & $\log (x / m)$ & \multicolumn{1}{c}{$\log x e$} & $\log (x / m)$ \\
\hline 40 & -2.23 & -0.0026 & -1.14 & -0.032 & -1.939 & -0.005 & -1.565 & -0.012 \\
50 & -2.21 & -0.0027 & -1.13 & -0.034 & -1.928 & -0.005 & -1.555 & -0.012 \\
60 & -2.19 & -0.003 & -1.10 & -0.036 & -1.906 & -0.005 & -1.543 & -0.013 \\
70 & -2.13 & -0.003 & -1.08 & -0.038 & -1.857 & -0.006 & -1.538 & -0.013 \\
80 & -2.08 & -0.003 & -1.07 & -0.034 & -1.807 & -0.007 & -1.480 & -0.015 \\
90 & -2.02 & -0.004 & -1.08 & -0.038 & -1.763 & -0.008 & -1.457 & -0.015 \\
100 & -2.01 & -0.004 & -1.09 & -0.036 & -1.763 & -0.008 & -1.446 & -0.016 \\
110 & -2.01 & -0.004 & -1.11 & -0.036 & -1.764 & -0.007 & -1.439 & -0.016 \\
120 & -2.02 & -0.004 & -1.12 & -0.035 & -1.759 & -0.007 & -1.465 & -0.015 \\
130 & -2.05 & -0.004 & -1.13 & -0.033 & -1.767 & -0.007 & -1.472 & -0.015 \\
\hline
\end{tabular}

Table 5. Mean Freundlich data on cotton oils bleaching $(n=3)$.

\begin{tabular}{ccccccccc}
\hline & \multicolumn{2}{c}{$\mathrm{Kaj} / 5 \%$} & \multicolumn{2}{c}{$\mathrm{Che} / 20 \%$} & \multicolumn{2}{c}{$\mathrm{Bud} / 5 \%$} & \multicolumn{2}{c}{ Che/5\% } \\
\hline $\mathrm{Temp} /{ }^{\circ} \mathrm{C}$ & \multicolumn{1}{c}{$\log x e$} & $\log (x / m)$ & $\log x e$ & $\log (x / m)$ & $\log x e$ & $\log (x / m)$ & $\log x e$ & $\log (x / m)$ \\
\hline 40 & -2.23 & -0.0026 & -1.14 & -0.032 & -1.939 & -0.005 & -1.565 & -0.012 \\
50 & -2.21 & -0.0027 & -1.13 & -0.034 & -1.928 & -0.005 & -1.555 & -0.012 \\
60 & -2.19 & -0.003 & -1.10 & -0.036 & -1.906 & -0.005 & -1.543 & -0.013 \\
70 & -2.13 & -0.003 & -1.08 & -0.038 & -1.857 & -0.006 & -1.538 & -0.013 \\
80 & -2.08 & -0.003 & -1.07 & -0.034 & -1.807 & -0.007 & -1.480 & -0.015 \\
90 & -2.02 & -0.004 & -1.08 & -0.038 & -1.763 & -0.008 & -1.457 & -0.015 \\
100 & -2.01 & -0.004 & -1.09 & -0.036 & -1.763 & -0.008 & -1.446 & -0.016 \\
110 & -2.01 & -0.004 & -1.11 & -0.036 & -1.764 & -0.007 & -1.439 & -0.016 \\
120 & -2.02 & -0.004 & -1.12 & -0.035 & -1.759 & -0.007 & -1.465 & -0.015 \\
130 & -2.05 & -0.004 & -1.13 & -0.033 & -1.767 & -0.007 & -1.472 & -0.015 \\
\hline
\end{tabular}

$\log (x / m)$ and $\log x e$ for four clays used in the study namely Kajansi, Kawuku, Budadiri and Chelel. As the representative data in Table 4 and Table 5 showed decrease in the relative residual quantities of impurities in oils within the temperature range between $40^{\circ} \mathrm{C}$ and $90^{\circ} \mathrm{C}$, it can be inferred that effective bleaching took place. As bleaching is accompanied by enthalpies of adsorption, decrease in relative residual impurities with increase in temperature and concentration of acid used to leach the clays should give rise to increase in enthalpies of adsorption for the clays.

The data in Table 4 and Table 5 shows that the extent of adsorption of impurities from vegetable oils increased as temperature of clay activation increased, proving that Freundlich adsorption isotherms can be developed for the bleaching of vegetable oils using clays. The method used in this study to predict adsorption of impurities in vegetable oils was successfully employed in bleaching hazelnut oil to investigate the applicability of the Langmuir and Freundlich equations and to elucidate the adsorption characteristics of oil on bentonite EY-09 (Bensan Co. Ltd., Edirne, Turkey) [23].

The average data in Table 4 and Table 5 was plotted to yield Freundlich isotherms shown in Figure 3 and Figure 4. The enthalpies of adsorption increased with increase in temperature and concentration of acid used to 


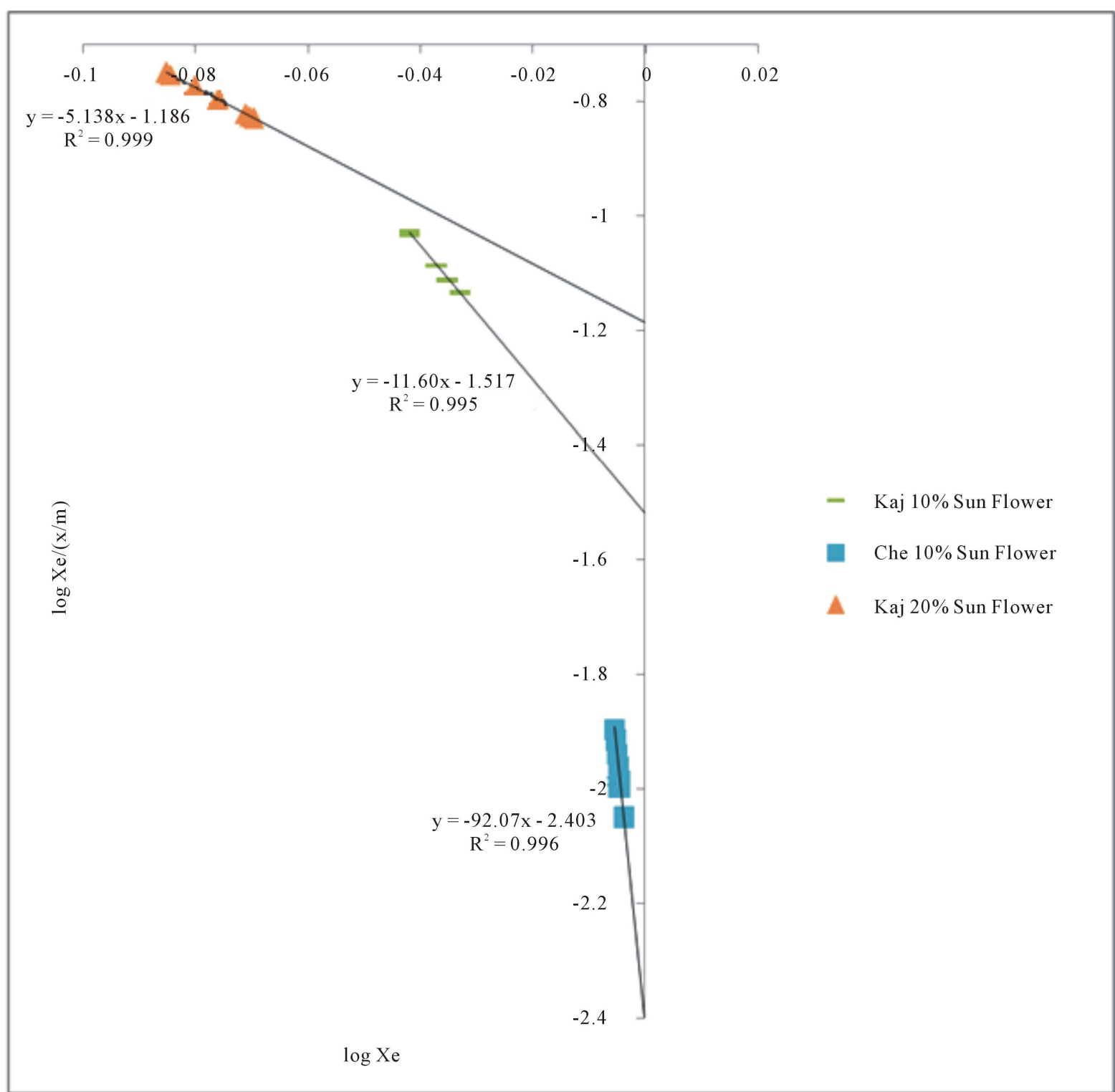

Figure 3. Freundlich isotherm for sunflower oil bleached using Chelel clay leached in $10 \%$ acid.

leach the clays. The linearity of the plots in Figure 3 and Figure 4 indicated that Freundlich adsorption occurred during the bleaching of both sunflower and cotton seed oils.

The isotherms for both sunflower and cotton seed oils followed the Freundlich equation in a manner similar to the adsorption isotherms of decolourisation of maize oil. This indicated the existence of heterogeneous adsorption sites on the solid's surface [25].

The Figure 3 and Figure 4 showed linearity in the temperature ranges between $40^{\circ} \mathrm{C}$ and $110^{\circ} \mathrm{C}$ depicting that Freundlich isotherms are observed when adsorption occurs on clays if thermally activated at temperatures below $110^{\circ} \mathrm{C}$ [7]. The coefficient of linearity of Freundlich adsorption isotherms, $\mathrm{R}^{2}$ for the kaolinite rich clays ranged from as low as $0.890 \pm 0.002$ for Seeta and Umatengah clays to as high as $0.998 \pm 0.002$ for Kawuku, Chodah and Kajansi clays. This revealed the acidity of kaolinite rich clays acquired low capacity to bind coloured impurities. So they would easily become saturated with impurities and deviate from linearity of the Freundlich isotherms [42].

The coefficients of linearity of Freundlich adsorption isotherms for smectite-rich clays ranged from $0.911 \pm$ 0.002 for Budadiri and Siron clays to $0.996 \pm 0.002$ for Mutufu and Chelel clays showing that these clay matrices 


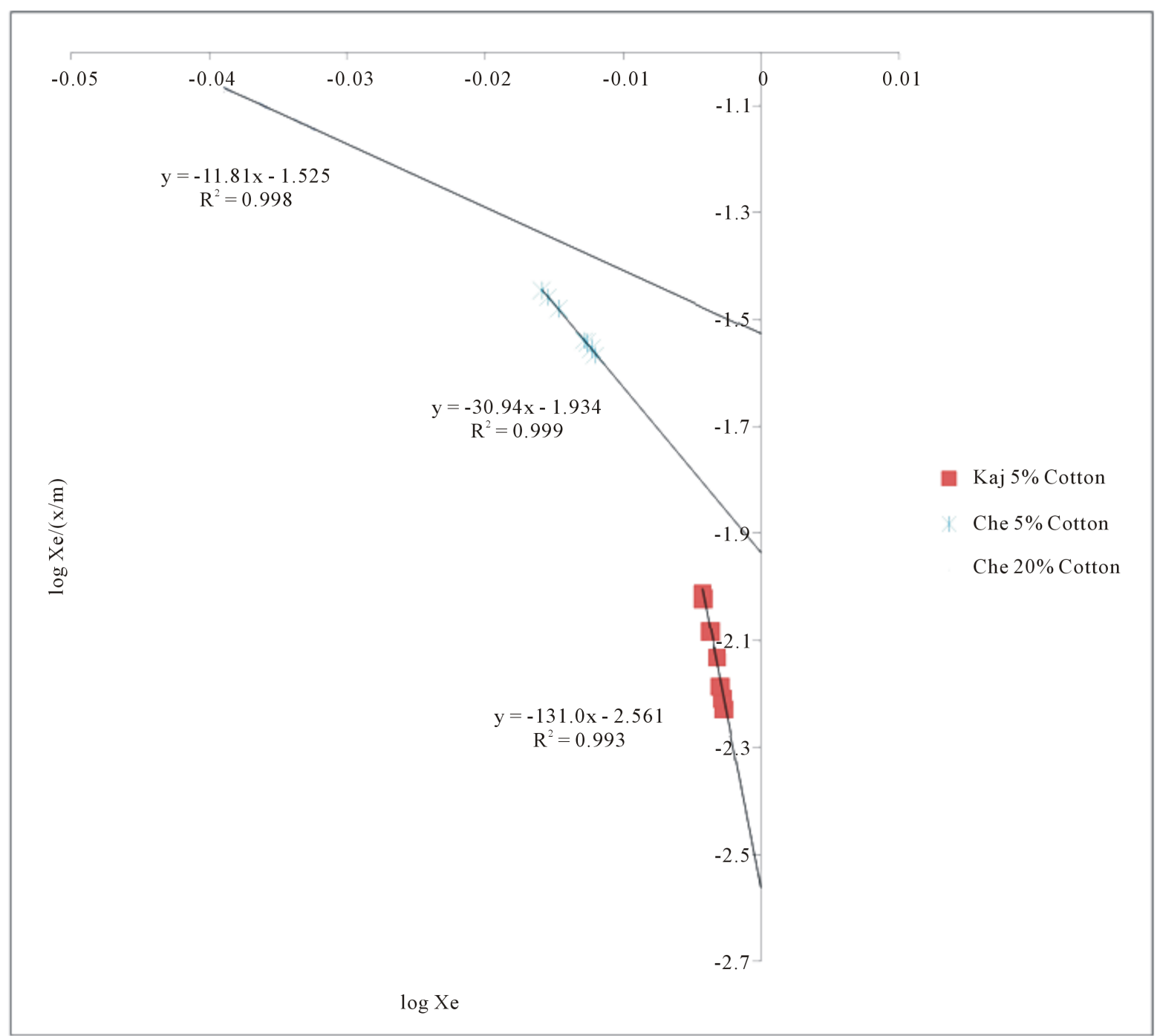

Figure 4. Freundlich isotherm for cotton oil bleached using Kajansi clay leached in 5\% acid.

did not have limitations resulting from overcrowding, steric interference, thermodynamic instability at high impurity concentrations (Hundal, 1988). The strongly adsorbing clays have been better described by the Freundlich isotherms within lower concentration ranges [31].

As Freundlich adsorption isotherms assume monolayer adsorption capacity complications arise when clays exhibit multi-layer adsorption tendencies and this causes deviation from linearity. Clays with poor adsorption capacities deviated from Freundlich isotherms because they easily got saturated with impurities from oils leading to steric interactions between the adsorbed and unadsorbed impurities [42]. The amount of impurities in vegetable oils that get adsorbed on clay matrices change with small changes in the equilibrium bulk concentration and this was reflected in the deviation of coefficient of linearity from unity.

As smectite-rich clays showed higher coefficients of linearity than kaolinite-rich clays, it can be inferred that acid-leached smectites obey Freundlich adsorption more closely than kaolinite-rich clays [30]. Hence differences in clays can be elucidated using Freundlich isotherms.

Activation of bleaching clays at higher temperatures than $100^{\circ} \mathrm{C}$ changes the crystallinity of the clays through loss of water of crystallisation. This causes deviation of coefficients of linearity form near unity. The values of the Freundlich constant $k$ and $n$ were obtained from plots of $\log x e(x / m)$ against logxe. The vertical intercept is $k$ and slopes of the linear graphs is, $n$ characterising the bleaching power of the clay and the manner in which impurities adsorb on the clay respectively [38] [43]-[45]. The values of $k$ and $n$ were calculated from Figure 3 and 
Figure 4 and tabulated in Table 5 and Table 6.

The larger the value of Freundlich constant, $k$ the better the clay at removing impurities from the vegetable oils. The values of $\mathrm{k}$ for any clay increased with increase in strength of the acid used to leach the clay because leaching with more concentrated acids resulted in creation of more impurity adsorption sites in the resulting clay matrix than when lower concentrations of acids were used. As the value of $\mathrm{k}$ for Chelel clay leached with $20 \%$ acid was highest, it can be concluded the clay had the highest bleaching strength among clays studied. [7].

The clay with higher $k$ value bleached better than one with smaller $k$. The value of the Freundlich constant $n$ is used to determine the range of decolourisation within which the adsorbent is most effective. A clay with a high $n$ will be relatively effective at binding impurities in oils but relatively inefficient at bleaching oil to a low colour value. The opposite is true for an adsorbent with a low $n$ value. A high $n$ value is desirable but not at the expense of $k$ [6]. From Figure 4 and Figure 5, values of the Freundlich constants, $\mathrm{n}$ and $\mathrm{k}$ have been calculated and tabulated as shown in Table 6 and Table 7.

The values of the Freundlich constants obtained in this study are very close to those obtained by Topallar (1998) bleaching sunflower seed oils with bentonites [7]. It was shown that physical adsorption occurred during the bleaching processes. There is close agreement in these values indicating that adsorption processes for impurities in vegetable oils closely follows the principles set up by Freundlich for the adsorption from solutions. The differences in values obtained arose from neat oil being used yet Topallar used dilute oil solutions in hexane.

The values of Freundlich constant, $n$, decreased with increase in concentration of the acid used to leach the clay because the strength of the leaching acid increased proportionately with the increase in the capacity of the clay to adsorb as long as the concentration of the acid is not greater than $40 \%$ by mass [46]. The differences in bleaching efficiency of the clays used in this study appeared to be due to differences in the physical and chemical properties of the bleaching media developed as a result of leaching clays. And this is similar to what was advanced when cotton-seed oil was bleached using acid-activated montmorillonite [47].

The kaolinite-rich clays from Central Uganda had bigger values of Freundlich constant $n$ because these clays were not as strongly affected by acid-leaching as compared to the smectite-rich clays from Sironko and Kapchorwa. Kajansi and Chelel clays gave very nearly equal values of $n$ yet their origins are different probably because Kajansi clays had equally as high iron and feldspar content as volcanic sediments. It is not surprising that Kajansi clays showed very high bleaching capabilities [48]. The Freundlich constant $k$ increased with increase in temperature for a given oil showing that the formation of adsorptive sites on the clay rose. In this respect the acid-activated clays behaved like the Turkish clay used in bleaching hazelnut oil [23].

When comparing Freundlich and Langmuir isotherms, it was found that the Freundlich isotherms could be

Table 6. Freundlich constants ( $n$ and $k$ ) for kaolinite-rich clays.

\begin{tabular}{ccccccccccc}
\hline \multicolumn{1}{c}{ Oil } & \multicolumn{3}{c}{ Kajansi clay } & \multicolumn{5}{c}{ Kawuku clay } \\
\hline & & Raw & $5 \%$ & $10 \%$ & $20 \%$ & Raw & $5 \%$ & $10 \%$ & $20 \%$ \\
\hline Cotton & $n$ & -159.2 & -131.0 & -91.7 & -50.2 & -522 & -321 & -221 & -184 \\
Cotton & $k$ & 12.65 & 12.56 & 12.46 & 12.16 & 6.19 & 4.72 & 2.90 & 2.21 \\
Sunflower & $n$ & -58.4 & -16.1 & -11.6 & -5.14 & -10.2 & -9.23 & -8.92 & -7.25 \\
Sunflower & $k$ & 2.20 & 1.66 & 1.52 & 1.19 & 2.31 & 1.72 & 1.42 & 1.12 \\
\hline
\end{tabular}

Table 7. Freundlich constants ( $n$ and $k$ ) for nontronite-rich clays.

\begin{tabular}{|c|c|c|c|c|c|c|c|c|c|}
\hline \multirow[t]{2}{*}{ Oil } & \multicolumn{5}{|c|}{ Budadiri clay } & \multicolumn{4}{|c|}{ Chelel clay } \\
\hline & & Raw & $5 \%$ & $10 \%$ & $20 \%$ & Raw & $5 \%$ & $10 \%$ & $20 \%$ \\
\hline Cotton & $n$ & -205.3 & -169.3 & -80.4 & -25.2 & -119 & -30.9 & -15.8 & -11.8 \\
\hline Cotton & $k$ & 13.60 & 13.31 & 12.81 & 12.67 & 12.53 & 1.93 & 1.41 & 1.35 \\
\hline Sunflower & $n$ & -9.6 & -8.7 & -7.2 & -5.70 & -161 & -128 & -92.1 & -49.9 \\
\hline Sunflower & $k$ & 1.41 & 1.28 & 1.16 & 1.07 & 2.64 & 2.55 & 2.41 & 2.16 \\
\hline
\end{tabular}


explained by assuming that the pigments were adsorbed on stronger acid sites in smaller pores at low concentration and then larger ones when the concentration increased [17]. The amount adsorbed increased with rise in adsorption temperatures from $70^{\circ} \mathrm{C}$ to $110^{\circ} \mathrm{C}$ and the heat of adsorption was less than $10 \mathrm{~kJ} / \mathrm{mol}$. The relation between the quantities of colouring matter removed onto the bleaching medium and the equilibrium concentration showed agreement with Freundlich and Langmuir adsorption isotherms [6]. It has been shown that clays from volcanic sediments of Mountain Elgon were more efficient at bleaching alkali refined oils than earths from the non volcanic sediments of Central Uganda and Kumi.

The values of the Freundlich constant, n, calculated using cotton-seed oils are much larger than the values calculated using sunflower-seed oils because the extent of bleaching of cotton seed oils was not as high as that for sunflower-seed oils. Generally, the concentration of impurities (colouring materials) in cotton-seed oils is higher than for sunflower-seed oils so only smectite-rich clays like Chelel and Budadiri samples had very strong decolourising effects on cotton oils. This is reflected in the values of constants calculated. The values of Freundlich constants prove that the acid-leached Chelel clay is as good as a bentonite if activated under appropriate acid and temperature conditions. Characteristically, the Chelel clay had greater number of adsorption sites than any other clay and had chances of adsorbing impurities to beyond monolayer capacity so its value of $\mathrm{n}$ fell below 5.

The values of the Freundlich constants, $k$, were low for kaolinite-rich clays from central Uganda showing that these clays had lower bleaching capacity than the smectite-rich clays from volcanic sediments. The values of $k$ for the kaolinite-rich clays were in the range $-5 \times 10^{-3}$ to $-5.6 \times 10^{-3}$ for cotton seed oils showing that the clays had less capacity to adsorb impurities in cotton seed oils than for impurities in sunflower seed oils for which the $\mathrm{k}$ values were found to be in the range -0.029 to -0.1132 [7]. This clearly proved that the bleaching ability of clays depends largely on the smectite content. Acid-leached clays with high smectite content bleach much better than clays with low smectite content. However, in the absence of smectite-rich clays, kaolinite clays may substitute and the quantity used must be much larger than for smectites to bring about a similar effect because of their lower bleaching capacity.

The fact that the values of the Freundlich constant, $k$, for Chelel clays was of the same magnitude as that determined for bentonite EY-09 by Topallar H. (1998) showed that the Chelel clay has special characteristics like the already identified bentonites on world markets. The higher values of $k$ for the Chelel clays than other clays studied indicated that this particular clay when acid leached gains a very high decolourising/bleaching power [20] [49] [50].

The Freundlich constant, $k$, values varied from as low as -0.004 for raw, unleached Chelel clay to as high as -0.0692 for clay leached with $20 \%$ acid, and this showed that this clay rapidly responded to acid-leaching. The values for bentonites lie in range -0.06 to -0.095 [7]. Although the Chelel clay is very poor at bleaching when it has not been leached with the acid due to high levels of sodium, calcium and potassium ions which retard bleaching [37], acid leaching removed these octahedral ions leading to higher bleaching power.

The clay matrices used to bleach the oils were heterogeneous because they have Broensted and Lewis centres and as well contain different phases present in clays, such as kaolinite, nontronite and illite layers, which also have active centres on their surfaces. Similarly, heterogeneity of Cyprus bentonite was attributed both to different active centres on the smectite surface (Broensted and Lewis centres) and to the different phases present in bentonite, such as illitic layers and clinoptilolite, which also have active centres on their surfaces as the clay was a mixture of illite and smectite [26] [47].

Another brand of Freundlich isotherms is obtained by plotting the $\log _{e}$ relative residual impurity concentration, lnxe, against the reciprocal of the absolute temperature at which the bleaching process was performed. These Freundlich isotherms are used to determine the enthalpy of adsorption. The data of in Table 8 was used to plot Figure 5 from which the enthalpy of adsorption was calculated.

Figure 5 consist of linear graphs indicating that Freundlich adsorption occurred during the bleaching of cotton and sunflower seed oils at temperatures in the range between $40^{\circ} \mathrm{C}$ and $90^{\circ} \mathrm{C}$.

The $\mathrm{R}^{2}$ values for Freundlich isotherms in Figure 5 range from $0.920 \pm 0.030$ to $0.980 \pm 0.030$ for kaolinite rich clays and $0.950 \pm 0.030$ to $0.990 \pm 0.030$ for smectite rich clays showing that the strongly adsorbing clays, derived from clay deposits mined from areas of past volcanic activity, have been better described by the Freundlich isotherms within lower concentration ranges [31]. As Freundlich adsorption isotherms assume monolayer adsorption capacity, complications arise when clays and clays minerals exhibit multi-layer adsorption tendencies at high impurity concentrations; causing deviations from linearity of the isotherms plotted. Clays with poor 
Table 8. Freundlich data on bleached oils.

\begin{tabular}{cccc}
\hline $1000 / T / \mathrm{K}^{-1}$ & In $x$ for $10 \%$ leach & In $x e$ for $20 \%$ leach & In $x e$ for $10 \%$ leach \\
\hline 3.195 & -0.006 & -0.013 & -0.002 \\
3.096 & -0.006 & -0.015 & -0.002 \\
3.003 & -0.007 & -0.021 & -0.003 \\
2.915 & -0.007 & -0.022 & -0.004 \\
2.833 & -0.008 & -0.024 & -0.004 \\
2.755 & -0.010 & -0.027 & -0.006 \\
& Sunflower & Oil & Cotton oil \\
\hline
\end{tabular}

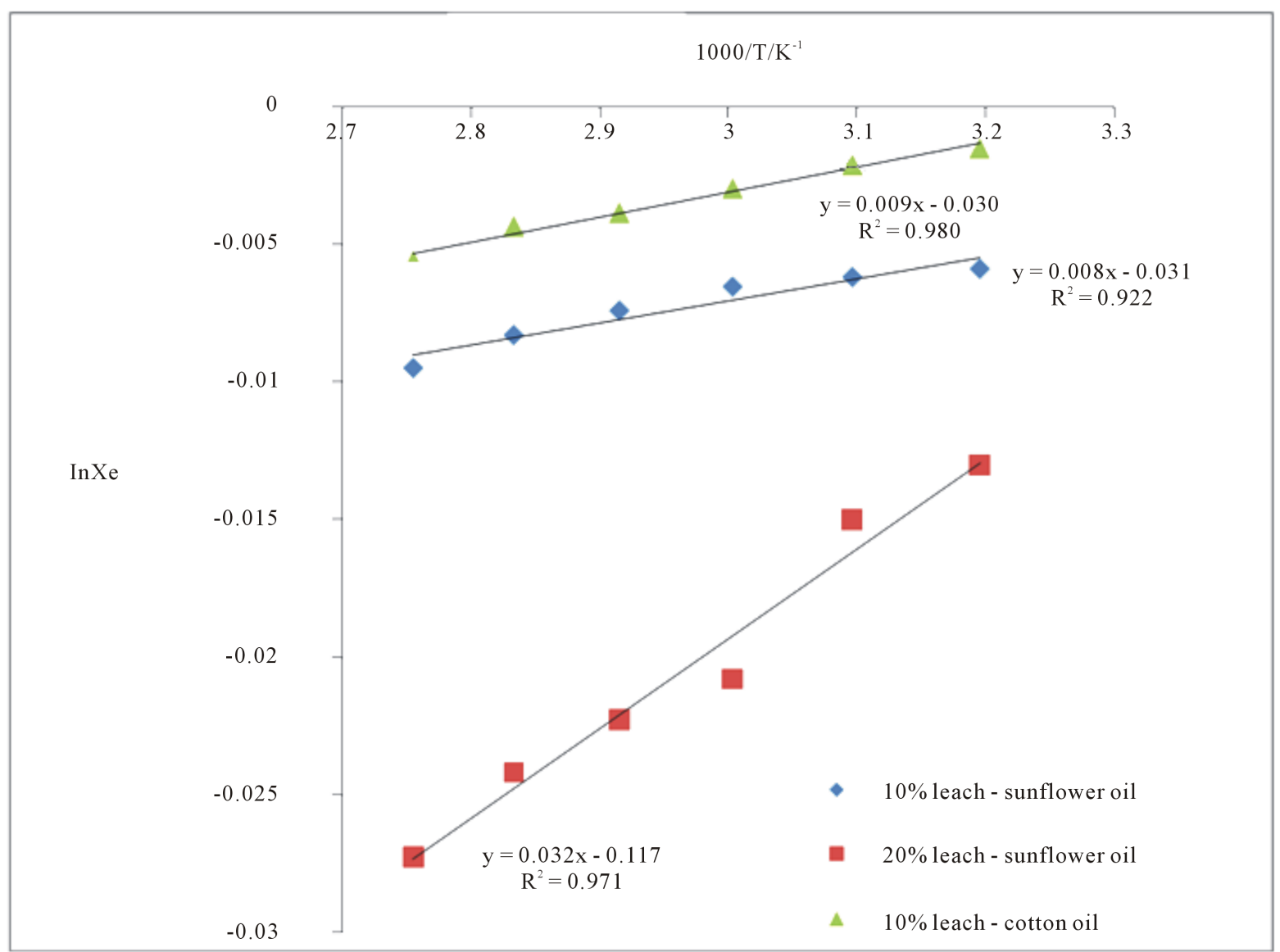

Figure 5. Freundlich isotherm for sunflower oil bleached with Kajansi leached in 5\% acid.

adsorption capacities deviated from Freundlich isotherms because they easily got saturated with impurities from oils leading to steric interactions between the adsorbed and unadsorbed impurities [42].

As Langmuir and Freundlich isotherms showed very high degree of linearity, it has been proposed that all acid-leached clays irrespective of their origin developed very high adsorptive tendencies for the impurities in the oils being bleached and this coincides with information published by the European Group of Clay Analysts [51]. This showed that clay minerals or aluminosilicates in general, once acid-leached, turn into silica hydrate or silicic acid. So di-octahedral and tri-octahedral silicates can be turned to bleaching earth, but the concentration of acid used, temperature at which the reactions are performed and duration of time over which the reactions are allowed to occur will determine the bleaching capacity the clay acquires. 
The heat of adsorption, $\Delta H a$, may be calculated in a manner similar to that used to calculate the heat of vaporisation of a liquid using the following modification of the Clausius-Clapeyron equation, (10) below:

$$
\frac{\mathrm{d} \ln P}{\mathrm{~d} T}=\frac{\Delta H a}{R T^{n}}
$$

and integration of the above equation gives:

$$
\ln P=\frac{-\Delta H a}{R T}+c
$$

where $c$ is the integration constant and for the bleaching process, this equation can be written as:

$$
\ln x e=\frac{-\Delta H a}{R T}+c
$$

Using the values of $x e$ and 1000/T the data in Table 8, Figure 5 were obtained and the enthalpy of adsorption, $\Delta H a$ was calculated from the slopes of the lines obtained and tabulated as shown in the Table 9.

As the decolourisation of oils optimally occurred at temperatures ranging from $70^{\circ} \mathrm{C}$ to $110^{\circ} \mathrm{C}$, it can be inferred that within this temperature range the crystal structure of the clay matrices is not greatly changed as water of crystallinity would not have been lost [36] (Dandy 1967). This evidence is also used to indicate that the water or hydroxyl groups in the clays play a major role since the gradient of the graphs in Figure 5 increased with increase the concentration of the acid used to leach the clay depicting that acid-activation of the clay greatly enhanced the bleaching capacity of any clay because acid-leaching removed octahedral ions like sodium, magnesium, calcium and potassium ions from the clay matrix which was established to retard bleaching [37] [40]. The heats of adsorption, $\Delta H a$, in $\mathrm{kJ} \cdot \mathrm{mol}^{-1}$ obtained from the slopes of the lines obtained in the plot of lnxe versus 1000/T are given in the Table 9.

The adduced data show that the Freundlich adsorption equation is very applicable in the bleaching of sunflower and cotton-seed oils. Although the values obtained are less than those obtained for adsorption from gaseous phase, the fact that energy is evolved confirms the applicability of the Freundlich isotherms to the decolorization of sunflower and cotton seed oils [4].

The data in Table 7 has values of adsorption enthalpies increasing as the concentration of the acid used to leach the clay matrices increased showing that acid-leaching increased the capacity of all the clays studied to adsorb impurities in the vegetable oils [21]. The negative values of heat of adsorption showed that the adsorption process is exothermic in nature because a given amount of heat is evolved during the bleaching process. The fact that the values enthalpies of adsorption are less than $20 \mathrm{~kJ} \cdot \mathrm{mol}^{-1}$ was argued [7] [20] to depict that the adsorption process of impurities on clay material occurred by the physi-sorption process, involving weak van der Waal's forces only. Similarly, the heat evolved during adsorption of impurities on Turkish bentonite were in the range of $0.32-1.03 \mathrm{~kJ} \cdot \mathrm{mol}^{-1}$ was less than $20 \mathrm{~kJ} \cdot \mathrm{mol}^{-1}$. The forces between the adsorbent and adsorbate appeared to be van der Waals forces [7] [23]. This was further proved by the fact that impurities adsorbed on clay could be extracted from the clay using solvents like butanone, diethyl ether, propanone or isohexane at room temperature.

\section{Table 9. The enthalpies of adsorption.}

\begin{tabular}{ccccccccc}
\hline \multirow{2}{*}{ Clay type } & \multicolumn{2}{c}{ Kajansi } & \multicolumn{2}{c}{ Kawuku } & \multicolumn{2}{c}{ Budadiri } & \multicolumn{2}{c}{ Chelel } \\
\cline { 2 - 8 } & Cotton oil & Sunflower oil & Cotton oil & Sunflower oil & Cotton oil & Sunflower oil & Cotton oil & Sunflower oil \\
\hline Percentage leach & & & & $10^{-3} \Delta \mathrm{Ha} / \mathrm{kJ} / \mathrm{mol}^{-1}$ & & & \\
$0 \%$ & -7.9 & -45.3 & -7.8 & -13.75 & -1.7 & -21.7 & -14.6 & -18.8 \\
$5 \%$ & -9.6 & -25.4 & -10.4 & -25.1 & -16.2 & -29.8 & -21.5 & -26.4 \\
$10 \%$ & -18.3 & -54.4 & -16.3 & -25.1 & -16.2 & -29.8 & -21.5 & -29.4 \\
$20 \%$ & -35.5 & -113.2 & -29.6 & -60.62 & -28.7 & -75.04 & -35.8 & -44.08 \\
\hline
\end{tabular}


However, the data in Table 9 has heats of adsorption which were less than what were produced when testing bentonites because the clays used in this study either contained no smectites or very low percentages of smectites [7]. Additionally, the smectites present had lower adsorption capacity than montmorillonite. So the values of enthalpy of adsorption could not compare with those obtained using activated montmorillonite. Whereas it was shown that decolorization of bleached vegetable oils depends on temperature and the time required for equilibrium to be attained and the energy of adsorption was $19.0 \mathrm{~kJ} \cdot \mathrm{mol}^{-1}$ [25] this study has found lower energy of adsorption because the clays and clay materials used were highly mixed up, with the dominant mineral in some of them being kaolinite with low capacity to bleach.

\section{Conclusions}

There was increased clarity of bleached oils measured in terms of decreased absorbance of bleached oils. This implied that the bleaching capacity of the selected clays increased with increase in concentration of acid medium and temperature at which the clay was activated.

Adsorption of oil impurities on clay follows both Langmuir and Freundlich isotherms provided the monolayer capacity of the clay was not exceeded.

\section{Recommendations}

Although much data has been adduced from the study involving interactions between acids and clays, vegetable oils and clays, there is need for further research in the case of zeolite interactions with acids and oils.

\section{Acknowledgements}

We thank Makerere University council for support, Mr. Edward Ssekubunga for the electric shaker used to sediment the clay samples, Prof Ludwig of Institut of Mineralogie for performing XRD on samples, Mr. Moses Nkolongo (RIP) for availing us chance to use the spectrophotometers in the analytical laboratories.

\section{References}

[1] Sabah, E.Ç. and Sabri, M. (2005) Sepiolite: An Effective Bleaching Adsorbent for the Physical Refining of Degummed Rapeseed Oil. Journal of the American Oil Chemists' Society, 82, 911-916.

[2] Langmuir, I. (1916) The Constitution and Fundamental Properties of Solids and Liquids. Part I. Solids. Journal of the American Chemical Society, 38, 2221-2295. http://dx.doi.org/10.1021/ja02268a002

[3] Freundlich, H.M.F. (1906) Über die Adsorption in Lösungen. Zeitschrift für Physikalische Chemie, 57, 385-470.

[4] Laidler, K.J. (1987) Chemical Kinetics. Harper and Row Publishers, New York.

[5] Boki, K.M. and Kawasaki, N. (1994) Bleaching of Rape Seed and Soybean Oils with Synthetic Adsorbents and Attapulgites. Journal of the American Oil Chemists' Society, 71, 595-601. http://dx.doi.org/10.1007/BF02540585

[6] Achife, J. and Ibemesi, J. (1989) Applicability of Freundlich and Langmuir Adsorption Isotherms in Bleaching of Rubber and Melon Seed Oils. Journal of the American Oil Chemists' Society, 66, 247-252. http://dx.doi.org/10.1007/BF02546069

[7] Topallar, H. (1998) Adsorption Isotherms of the Bleaching of Sunflower-Seed Oil. Turkish Journal of Chemistry, 22, 143-148.

[8] De Greyt, W.F., Kellens, M.J. and Huyghebaert, A.D. (1999) Effect of Physical Refining on Selected Minor Components in Vegetable Oils. Lipid, 101, 428-432. http://dx.doi.org/10.1002/(SICI)1521-4133(199911)101:11<428::AID-LIPI428>3.0.CO;2-T

[9] Rossi, M., Gianazza, M., Alamprese, C. and Stanga, F. (2001) The Effect of Bleaching and Physical Refining on Color and Minor Components of Palm Oil. Journal of the American Oil Chemists' Society, 78, 1051-1055. http://dx.doi.org/10.1007/s11746-001-0387-8

[10] Ng, M.H., Choo, Y.M., Ma, A.N., Chuah, C.H. and Mohd. Ali, H. (2004) Separation of Vitamin E (Tocopherol, Tocotrienol and Tocomonoenol) in Palm Oil. Lipids, 39, 1031-1035. http://dx.doi.org/10.1007/s11745-004-1327-y

[11] Puah, C.W., Choo, Y.M., Ma, A.N. and Chuah, C.H. (2007) The Effect of Physical Refining on Palm Vitamin E (Tocopherol, Tocotrienol and Tocomonoenol). American Journal of Applied Sciences, 4, 374-377.

[12] Zchau, W. (1981) Chapter 9: Bleaching. In: O’brien, R.D., Farr, W.E. and Wan, P.J., Eds., Introduction to Fats and Oils Technology, Second Edition, AOCS Press, Champaign. 
[13] Goh, E.M. (1991) Palm Oil Composition and Quality. Proceedings of the PORIM International Palm Oil Conference (Chemistry and Technology), 268-278.

[14] Car, R.A. (1978) Refining and Degumming Systems for Edible Oils and Fats. Journal of the American Oil Chemists' Society, 55, 765-771. http://dx.doi.org/10.1007/BF02682645

[15] Sadia, M.A. (1992) Degumming of Soybean Oil. Fasc., 45, 11-17.

[16] Patterson, H.B.W. (1992) Chapter 3: Adsorbents. In: List, G.R., Ed., Bleaching and Purifying Fats and Oils: Theory and Practice, American Oil Chemists' Society, Champaign.

[17] Boki, K.M., Kubo, T. and Tamura, N. (1992) Bleaching of Alkali Refined Vegetable Oils with Clay Minerals. Journal of the American Oil Chemists' Society, 61, 233-236.

[18] Mbah, B.J.M., Kamga, J.F., Nguetnkam, J. and Fanni, J. (2005) Adsorption of Pigments and Free Fatty Acids from Shea Butter on Activated Cameroonian Clays. European Journal of Lipid Science and Technology, 107, 387-394. http://dx.doi.org/10.1002/ejlt.200501149

[19] Hui, Y. (1996) Bailey’s Industrial Oil and Fat Products. John Wiley and Sons Inc., New York, 281-282.

[20] Rich, A.D. (1964) Some Basic Factors in the Bleaching of Fatty Oils. Journal of the American Oil Chemists' Society, 41, 315-321.

[21] Temuujin, J., Senna, M., Jadambaa, T., Burmaa, D., Erdenechimeg, S. and MacKenzie, K.J.D. (2006) Characterization and Bleaching Properties of Acid-Leached Montmorillonite. Journal of Chemical Technology \& Biotechnology, 81, 688-693. http://dx.doi.org/10.1002/jctb.1469

[22] Gregg, S.J. and Sing, K.S.W. (1997) Adsorption, Surface Area and Porosity. Academic Press, London, 197-199.

[23] Yuksel, B. (2003) Adsorption Isotherms in Bleaching Hazelnut Oil. Journal of the American Oil Chemists' Society, 80, 1143-1146.

[24] Siddiqui, M.K.H. (1989) One of These Physicochemical Properties Is Surface Acidity. Clay Minerals, 37, $385-395$.

[25] Christidis, G.E. and Kosiari, S. (2003) Decolorization of Vegetable Oils: A Study of the Mechanism of Adsorption of $\beta$-Carotene by an Acid-Activated Bentonite from Cyprus. Clays and Clay Minerals, 51, 327-333. http://dx.doi.org/10.1346/CCMN.2003.0510309

[26] Travis, C.L. and Etnier, E.L. (1981) A Survey of Sorption Relationships for Reactive Solutes in Soil. Journal of Environmental Quality, 10, 8-17.

[27] Fried, N. and Shapiro, R.E. (1956) Phosphate Supply Patterns of Various Soils. Soil Science Society of America Journal, 20, 471-475. http://dx.doi.org/10.2136/sssaj1956.03615995002000040007x

[28] Olsen, R.S. and Watanabe, F.S. (1957) A Method to Determine a Phosphorous Adsorption Maximum of Soils as Measured by Langmuir Isotherms. Soil Science Society of America Journal, 21, 144-149. http://dx.doi.org/10.2136/sssaj1957.03615995002100020004x

[29] Hundal, H.S. (1988) A mechanism of Phosphate Adsorption on Narrabri Medium Clay Loam Soil. Journal of Agricultural Science, 111, 155-158. http://dx.doi.org/10.1017/S0021859600082952

[30] Alemdaroglu, T. (2003) Investigation of the Surface Acidity of a Bentonite Modified by Acid Activation and Thermal Treatment. Turkish Journal of Chemistry, 27, 675-683.

[31] Kothawala, D.N., Moore, T.R. and Hendershot, W.H. (2008) Adsorption of Dissolved Organic Carbon to Mineral Soils: A Comparison of Four Isotherm Approaches. Geoderma, 148, 43-50. http://dx.doi.org/10.1016/j.geoderma.2008.09.004

[32] Vandenbruwane, J., De Neve, S., Hofman, G., Sleutel, S. and Hofman, G. (2007) Isotherm Models for Desired Organic Carbon (DOCS) and Nitrogen Sorption to Mineral Soil. Geoderma, 139, 144-153. http://dx.doi.org/10.1016/j.geoderma.2007.01.012

[33] Jaroniec, M. and Kruk, M. (1999) Standard Nitrogen Adsorption Data for Characterization of Nanoporous Silica. Langmuir, 15, 5410-5413. http://dx.doi.org/10.1021/la990136e

[34] Allen, S.J., Khader, K.K.H. and McKay, G. (1988) Mathematical Modeling of the Adsorption of Dyes. Environmental Pollution, 52, 39-53.

[35] Srinivasan, K.R. and Fogler, H.S. (1990) Adsorption of Toxic Organics on Modified Montmorillonite. Clay and Clay Minerals, 38, 287-293.

[36] Dandy, A.J. (1965) Bleaching Vegetable Oils with Kajansi, Koki and Mutaka Clays. Proceedings of the East African Academy, 3, 2-8.

[37] Balaras, P.K., Lezou, P. and Seiragakis, G. (1999) Mineralogical Society of London. Clay Minerals, 34, $221-312$.

[38] Boyd, S.A., Shaobai, S., Lee, J.F. and Mortland, M.M. (1988) Pentachlorophenol Sorption by Organo-Clays. Clays and 
Clay Minerals, 36, 125-130.

[39] Hassan, H.M. (2006) Structural and Chemical Alteration of Glauconite under Progressive Acid Treatment. Clay Minerals, 54, 491-499.

[40] Madejova, J., Andrejkovičová, S., Bujjdak, J., Ceklovsky, A., Hrachova, J., Valuchova, J. and Komadel, P. (2007) Characterization of Products Obtained by Acid Leaching of Fe-Bentonite. Clay Minerals, 42, 527-540.

[41] Proctor, A. and Toro-Vazquez, J.F. (1998) The Freundlich Isotherms in Studying Adsorption in Oil Processing. Journal of the American Oil Chemists' Society, 73, 1627-1633. http://dx.doi.org/10.1007/BF02517963

[42] Nodvin, S.C., Driscoll, C.T. and Likens, G.E. (1986) Simple Partitioning of Anions and Dissolved Organic Carbon in Soil. Soil Science, 142, 27-36. http://dx.doi.org/10.1097/00010694-198607000-00005

[43] Norris, F.A. (1964) Bailey’s Industrial Oil and Fats Products. Interscience, New York.

[44] Kaufmann, H.P. and Mukherjee, K.D. (1967) Neuzeitliche Technologie der Fette und Fettprodukte CXVI: Die Raffination der Fette. Chemische Revue über die Fett- und Harz-Industrie, 69, 463-472.

[45] Bijay, K.D.J., Jignesh, B.P., Vijay, K.P. and Vinay, R.P. (2000) Activated Clay. Journal of Oleo Science, 58, $257-263$.

[46] Gadzekpo, V.P.Y. and Mensah, S.G. (1991) Bleaching Palm Oil and Shea Butter Oils Using Acid-Leached Ghanaian Clays. Ghana Journal of Chemistry and Industry, 1, 197-201.

[47] Ujeneza, E., Njenga, H.N., Mbui, N.D. and Kariuki, D.N. (2014) Optimization of Acid Activation Conditions for Athi River Bentonite Clay and Application of the Treated Clay in Palm Oil Bleaching. IOSR Journal of Applied Chemistry (IOSR-JAC), 7, 29-38. www.iosrjournals.org

[48] Dandy, A.J. (1968) Bleaching Cotton Seed Oils with a Sepiolite. The Journal of Physical Chemistry, 72, $334-339$.

[49] Fahn, R. (1976) Bleaching Earths-Preparation, Properties, Practical Applications. Proceedings of the International Symposium, Brussels, 28-29 April 1976.

[50] Onal, M., Sarikaya, Y., Alemdaroglu, T. and Bozdogan, T. (2002) Effect of Acid Activation on Some Physico-Chemical Properties of Clays. Turkish Journal of Chemistry, 409-416.

[51] ECGA, European Clay Group Association (2002) Newsletter No.5, July 2002, 57-78. 